\title{
O Uso de um Aplicativo 3D para Ensino de Fisiologia
}

\section{Humana}

\author{
Ana Beatriz Vanderlei ${ }^{1}$, Ísis Raphaella Maria Ramos dos Santos ${ }^{1}$, Patrícia \\ Mariana Vasco de Góz ${ }^{2}$ \\ ${ }^{1}$ Universidade Federal de Pernambuco (CAV/UFPE) - Vitória de Santo Antão, \\ PE - Brasil \\ ${ }^{2}$ Professora da Rede Básica de Ensino de Pernambuco - Brasil \\ beatriz.vanderleidufpe.br, isis.raphaella@ufpe.br, \\ pmvg26@gmail.com
}

\begin{abstract}
Different technologies by which the students currently has access can be converted as an facilitate instrument's of study inside or outside Biology classroom. This paper aimed to analyze the affect of the uses of the application in the form of three-dimensional atlas of human body in human physiology classes. The activity was developed about didactic sequence with eight classhours. After the application of the didactic sequence, the knowledge's evolution of students was verified, both in descriptive and morphofunctional terms, indicating that the didactic strategy developed had constituted an excellent resource for the integration of knowledge with meaningful learning.
\end{abstract}

Resumo. As diferentes tecnologias, as quais o aluno tem acesso atualmente, podem ser convertidas em um instrumento facilitador do estudo dentro e fora da sala de aula de Biologia. O presente trabalho teve como objetivo analisar a influência do uso de um aplicativo na forma de atlas tridimensional do corpo humano nas aulas de fisiologia humana. A atividade foi desenvolvida em uma sequência didática com 8h/a. Após a aplicação da sequência didática, constatou-se a evolução dos conhecimentos dos alunos tanto em termos descritivos quanto morfofuncionais, indicando que a estratégia didática utilizada constituiu um excelente recurso para a integração do conhecimento com a aprendizagem significativa.

\section{Introdução}

Vivemos em uma época de grandes transformações tecnológicas e sociais, onde o conhecimento é lançado numa grande velocidade, o que demanda uma transformação de metodologias de ensino no contexto escolar [Oliveira et al. 2015]. O conhecimento deixou de ser apenas centrado na figura do professor e o aluno passou a ser protagonista do seu aprendizado. De acordo com a Base Nacional Comum Curricular (BNCC), a área de Ciências da Natureza, deve atuar na construção de conhecimentos contextualizados, 
buscando temas que sejam interessantes aos alunos e de relevância para seu desenvolvimento quanto ser social, preparando-os para tomada de decisões, proposição de alternativas, bem como fazer o uso criterioso de diversas tecnologias [Brasil 2017].

Com ampla modernização de mídias sociais, sistemas computacionais e recursos digitais [Wen 2016] os quais são extremamente acessíveis ao público [Ribeiro 2017], o professor pode apoderar-se de tais instrumentos para estimular o raciocínio investigativo do aluno e, ao mesmo tempo, torna-lo um personagem ativo na construção do conhecimento. Utilizando diferentes metodologias que estimulem a autonomia e respeitem a velocidade de aprendizagem de cada indivíduo, podemos criar um ambiente de ensino-aprendizagem interativo [Ribeiro 2017] e que se aproveite da curiosidade nata dos alunos envolvidos.

Vários estudos já consideram que o ensino, com o uso de tecnologias como softwares educacionais, os em 3D por exemplo, pode tornar as aulas mais atrativas e agradáveis motivando esses alunos e servindo como uma fonte de estudo alternativa estimulando e facilitando compreensão de determinados eventos, como os fisiológicos, por exemplo [Baldo 2017; Ribeiro 2017; Carneiro 2019; Rodrigues et al. 2019], despertando a curiosidade e a autonomia de cada indivíduo, possibilitando ao aluno noção da sua própria vida e do mundo que está inserido.

O estudo da Fisiologia Humana na Educação Básica se torna imprescindível, pois ajuda na formação crítica do indivíduo, bem como proporciona um conhecimento amplo do funcionamento do corpo humano, sendo assim fundamental para a manutenção da saúde e do bem estar, fazendo-se necessária uma ótima estruturação para a abordagem da temática. Logo, uma aprendizagem equivocada de qualquer conceito ou funcionamento, compromete todo esse mecanismo de auto compreensão por parte dos alunos [Correo Costa; Pansera-de-Araújo; Bianchi 2017].

A sistematização do funcionamento corporal humano é imaginada, muitas vezes, de forma estática, pelo fato do aluno recorrer apenas a imagens presentes nos livros didáticos. Entretanto, apesar de facilitar a compreensão do aluno, as imagens se usadas apenas para fins descritivos podem prejudicar a sua compreensão como uma unidade dinâmica, tridimensional e diversificada. Como resultado, temos um afastamento do objetivo de construção científica. Dentre os desafios do professor podemos ressaltar, neste caso, a necessidade de aproximar conteúdos complexos à realidade do aluno [Silva et al. 2017].

Dessa forma, para ajudar na compreensão da morfuncionalidade dos sistemas do corpo humano, usou-se o aplicativo Human Anatomy Atlas-2018, o qual o aluno pode explorar o corpo humano em uma realidade tridimensional. Nele é possível escolher a região que será observada, planos e secções corporais, órgãos isolados ou incluídos num sistema, dentre outras funcionalidades. Ademais, fornece informações sobre o órgão como localização, função e patologias associadas. Como recursos extras, há animações sobre o funcionamento de sistemas, quizzes para resolução, e produção de cards personalizados esquemas de observação para uso posterior.

A proposta do presente trabalho teve como objetivo avaliar o uso do aplicativo Human Anatomy Atlas-2018, como estratégia didática para a compreensão do funcionamento sistêmico e integrado do corpo humano. 


\section{Metodologia}

A sequência didática foi proposta para uma disciplina do Mestrado Profissional em Ensino de Biologia, sendo desenvolvida com 18 alunos do segundo ano do Ensino Médio da Escola Estadual Vigário Pedrosa, localizada no município de Escada-PE. Este plano de intervenção foi baseado na metodologia de abordagem qualitativa. 8h/aulas.

A implantação da sequência didática foi realizada em 4 encontros e utilizaram-se

$\mathbf{1}^{\mathbf{0}}$ encontro (2h/a) - Inicialmente foi aplicado foi um pré-teste, do tipo questionário, com quatro perguntas objetivas sobre a percepção dos alunos acerca dos sistemas do corpo humano e suas conexões. Após aplicação do questionário, foi solicitado que os alunos, em círculo, fechassem os olhos e realizassem observações sobre o funcionamento de seus corpos seguindo as orientações do professor. Por conseguinte, de forma oral, os alunos foram questionados sobre a interação e organização do funcionamento interno dos sistemas, seguido da exibição do documentário da National Geographic intitulado "A Incrível Máquina Humana". O encontro foi finalizado com um debate no qual os alunos expuseram sua opinião sobre o que foi abordado e escolheram três sistemas para serem estudados de forma conjunta.

$2^{\mathbf{o}}$ encontro (2h/a) - Aula expositiva dialogada sobre o funcionamento conjunto dos sistemas digestório, circulatório e respiratório. Para ajudar na compreensão do assunto abordado, foi utilizado o aplicativo de imagens tridimensional para computador Human Anatomy Atlas 2018 - The Complete 3D Human Body, (disponível em https://www.visiblebody.com). À medida que o assunto era explanado, foi acompanhado pelas imagens do aplicativo (Figura 01) no qual o professor manipulou de acordo com cada tópico abordado. A utilização do aplicativo permitiu que o professor explorasse a relação entre os sistemas de acordo com as indagações da turma.

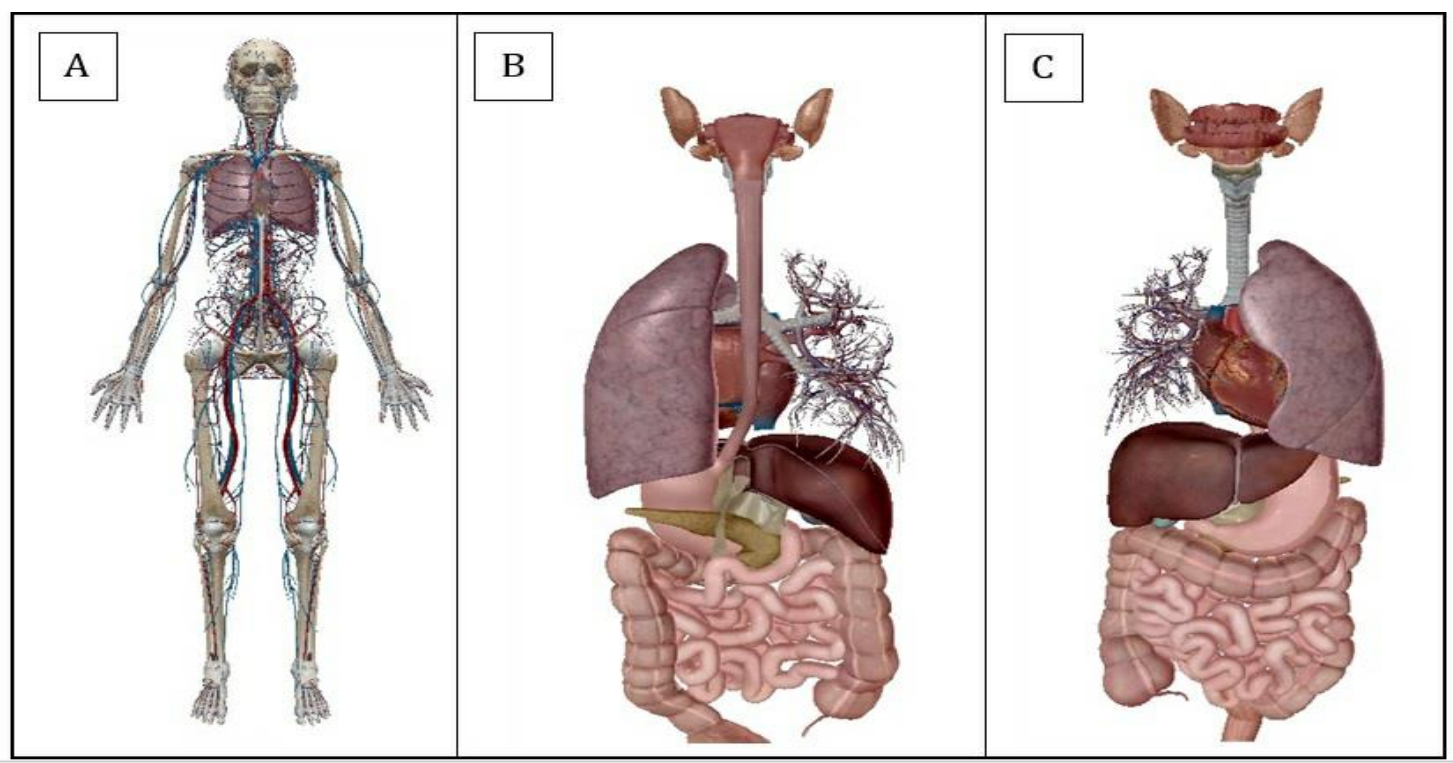

Figura 01: Imagens do aplicativo Human Anatomy Atlas 2018 - The Complete 3D Human Body. A: vista frontal do corpo formado pelos sistemas ósseo, cardiovascular e respiratório; B: vista anterior dos sistemas respiratório e 


\section{digestório, e parte do sistema cardiovascular; C: vista posterior dos sistemas respiratório e digestório, e parte do sistema cardiovascular.}

$3^{\text {o }}$ encontro (2h/a) - a turma foi dividida em pequenos grupos, e, seguindo a explicação da aula anterior, utilizaram o aplicativo para explorar o corpo humano e responder o pós-teste com as mesmas perguntas do pré-teste.

$4^{0}$ encontro (2h/a) - A sequência didática foi concluída no quarto encontro, no qual a turma dividida em três grupos construiu um modelo didático sobre um sistema trabalhado.

\section{Resultados e Discussão}

Entender o funcionamento dos sistemas do corpo humano pode ser complexo para grande parte dos alunos, pelo fato de apresentar diversos nomes característicos e cada órgão ter sua funcionalidade específica. Para tentar dirimir as principais dificuldades sobre o assunto e tentar deixá-lo mais fácil de compreensão foi usado um aplicativo de realidade tridimensional no processo de ensino-aprendizagem, além do uso do questionário, para a avalição da intervenção.

No primeiro momento da intervenção foi aplicado um pré-teste, de onde foram retirados de forma aleatória uma amostragem de 5 alunos para compor o seguinte quadro (as respostas foram transcritas seguindo a gramática e concordância do estudante):

\section{Quadro 1. Amostragem de respostas de pré-teste}

\begin{tabular}{|l|l|}
\hline \multicolumn{2}{|c|}{ 01: O corpo humano pode continuar trabalhando normalmente se algum sistema parar } \\
de funcionar?
\end{tabular}


O público alvo residem em uma área predominantemente rural e, a unidade escolar não dispõe de modelos didáticos para demonstração nas aulas de Biologia. Dessa forma, ao se trabalhar Fisiologia Humana, o aporte imagético é suprimido através do uso dos livros didáticos e materiais produzidos pelo professor. A turma apresenta um perfil participativo e questionador, o qual foi imprescindível para a condução das atividades. Também foi possível perceber que os estudantes possuíam conceitos prévios baseados no conhecimento popular e, na sua maioria, equivocados.

Analisando as respostas é possível perceber que, apesar do assunto, Fisiologia Humana já ter sido trabalhado em séries anteriores, os alunos ainda apresentam dificuldade em correlacionar as funções e interações sistêmicas, e isso se deve principalmente ao fato de cada sistema ser estudado separadamente e muitas vezes de forma fragmentada. Também é possível perceber que, apesar das imagens presentes nos livros didáticos e das utilizadas pelo professor, a projeção da organização interna humana ainda é confusa. Após o documentário, os alunos relataram admiração e curiosidade com o funcionamento do corpo humano, dando enfoque principalmente a organização sistêmica. Neste momento também foi possível perceber que alguns alunos apresentaram desconforto durante a aparição de imagens dos órgãos internos, como o estômago, por exemplo, e esses mesmos alunos expuseram que não se sentiam confortáveis com imagens reais. O diálogo com a turma permitiu a escolha dos três sistemas que mais chamaram atenção dos alunos.

No segundo momento, foi introduzido o uso do aplicativo Human Anatomy Atlas 2018 - The Complete 3D Human Body. O professor iniciou a aula expositiva com utilização do aplicativo, projetando uma imagem tridimensional de um corpo humano completo, e enquanto explicava o funcionamento do Atlas, ia retirando da exibição os sistemas até sobrarem apenas os aqueles escolhidos pelos estudantes para aprofundamento anteriormente. À medida que as explicações eram realizadas, o professor escolheu órgãos específicos, indicando localização sua localização, órgãos próximos, cortes anatômicos e utilizou as informações disponíveis no aplicativo sobre doenças relacionadas, tamanho, funções e etc., nesse caso sendo necessária a tradução para o português. Diante dessa abordagem, os alunos apresentaram um interesse maior do que o documentário. Ao serem indagados do porquê, explicaram que a ausência de partes que lembrem sangue facilitou o acompanhamento das imagens.

Outro ponto de interesse perceptível foi o manuseio do aplicativo, já que este permite acrescentar ou retirar estruturas, vista de diferentes posições e secções anatômicas, visualização específica de determinadas partes do corpo, além de informações (em inglês) sobre os órgãos. A utilização dessa ferramenta estimulou a participação dos alunos, quando comparada a aulas anteriores ministradas pelo mesmo professor. Além disso, ocasionou perguntas que não estavam diretamente correlacionadas ao assunto abordado, mas que foram surgindo durante a aula. Ainda nesse momento, o professor buscou a reformulação de conceitos errôneos sobre o funcionamento do corpo humano identificados durante o primeiro momento. 
No terceiro encontro os alunos tiveram a oportunidade de manusear o aplicativo (Figura 02). A turma foi dividida em três grupos, e cada um escolheu um sistema trabalhado durante o segundo momento para analisar no Atlas. Com o acompanhamento do professor, os alunos escolheram as secções que gostariam de visualizar e manipularam de acordo com a sua curiosidade. Um ponto negativo foi a dificuldade de compreensão das palavras e explicações em inglês, que foi suprida com o auxílio do professor. Os estudantes tiraram fotos e realizaram anotações que auxiliariam na atividade do quarto momento.
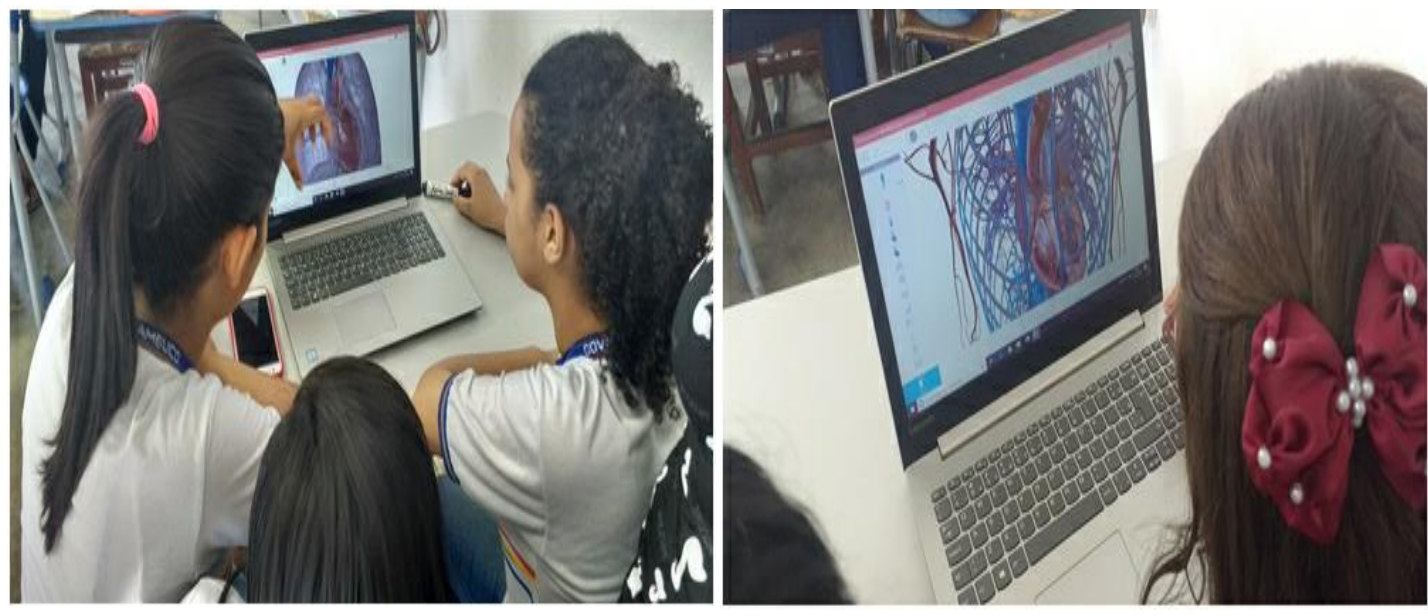

Figura 02: Manuseio do aplicativo Human Anatomy Atlas 2018 pelos alunos do 2o ano do Ensino Médio

Após essa atividade, cada grupo foi questionado oralmente pelo professor acerca do que acharam do aplicativo para as aulas. De forma sucinta, a opinião da maioria foi que facilitou a compreensão dos assuntos abordados, pois facilitava a formação de imagem mental sobre o interior do corpo humano, sem as partes "nojentas", segundo palavras dos estudantes. Elencaram ainda, que foi divertido usar o Atlas, pois pudera mover e observar do modo que escolheram.

(Quadro 02).

Por fim, os alunos responderam o pós-teste com as mesmas perguntas do pré-teste

Quadro 02: Amostragem de respostas do pós-teste.

\begin{tabular}{|c|c|}
\hline \multicolumn{2}{|c|}{$\begin{array}{l}\text { 01: O corpo humano pode continuar trabalhando normalmente se algum sistema parar } \\
\text { de funcionar? }\end{array}$} \\
\hline Aluno A & Não, pois todos os sistemas precisam funcionar juntos. \\
\hline Aluno B & Não porque um órgão não pode trabalhar sozinho, depende dos outros também. \\
\hline Aluno C & Sim, mas o funcionamento não é normal. \\
\hline Aluno D & $\begin{array}{l}\text { Não, porque um órgão influencia o trabalho de outro órgão. Se um parar, os outros } \\
\text { são prejudicados. }\end{array}$ \\
\hline Aluno E & Não, a paralisação irá comprometer todo o corpo. \\
\hline \multicolumn{2}{|r|}{ 02: Que exemplo de interação entre sistemas você pode citar? } \\
\hline Aluno A & \\
\hline Aluno B & A troca de gases no pulmão e a circulação. \\
\hline Aluno C & Os nutrientes e a glicose absorvidos no intestino e distribuído pelo sangue. \\
\hline Aluno D & Os nervos e a movimentação do corpo. \\
\hline Aluno E & A passagem do ar pelas cordas vocais. \\
\hline
\end{tabular}




\begin{tabular}{|l|l|}
\hline Aluno A & Os órgãos têm seu lugar certo para poder funcionar direito. \\
\hline Aluno B & É organizado. \\
\hline Aluno C & É igual pra todo mundo, porque os órgãos ficam em lugares específicos. \\
\hline Aluno D & Tudo tem uma ordem, porque precisam estar em seus lugares para funcionarem. \\
\hline Aluno E & Tudo em seu lugar específico e protegido pelos ossos e músculos. \\
\hline \multicolumn{2}{|c|}{ 04: Como a tecnologia ajuda a estudar o corpo humano? } \\
\hline Aluno A & Ajuda a filmar e tirar foto, para os médicos e a gente poder estudar. \\
\hline Aluno B & $\begin{array}{l}\text { Faz com que a gente possa ver tudo por dentro, como funciona. Ajuda a gente a } \\
\text { estudar também. }\end{array}$ \\
\hline Aluno C & Ajuda a gente a estudar, feito o aplicativo do computador. \\
\hline Aluno D & $\begin{array}{l}\text { Faz com que a gente tenha as imagens dos órgãos nos livros, na internet e nos } \\
\text { documentários. }\end{array}$ \\
\hline Aluno E & É útil para os médicos estudarem o corpo, mas também pra ajudar os estudantes. \\
\hline
\end{tabular}

Comparando as respostas do pré-teste e do pós-teste é nítida a evolução argumentativa na amostragem, caracterizando uma melhora significativa da aprendizagem se comparada ao início da intervenção como observadas nas respostas da pergunta 01, na qual os estudantes indicam a compreensão da necessidade de funcionamento integrado dos sistemas. Para a pergunta 02, apesar da ausência de uma resposta, os estudantes identificaram uma maior diversidade de órgãos e funções, quando comparada às respostas do pré-teste.

Na pergunta 03, houve uma similaridade entre as respostas do pré e pós-teste, tendo este último apresentado uma melhor argumentação. E por fim, na pergunta 04 temos um retorno do uso do Atlas nas aulas, conforme respostas do pós-teste.

No último encontro ocorreu a produção de modelos didáticos baseados no trabalho com o aplicativo Human Anatomy Atlas - 2018. Foi possível constatar que durante a confecção dos modelos os alunos não recorreram ao uso de imagens da internet ou de livros didáticos, utilizando como base as imagens e anotações que obtiveram no aplicativo e demostraram maior interesse na participação da atividade.

\section{Considerações Finais}

Tornou-se evidente que a prática diferenciada em sala de aula colabora para a motivação e interesse dos alunos pelo tema discutido, contribuindo efetivamente para participação dos alunos na esfera educacional. A percepção dos alunos acerca da organização e funcionamento dos sistemas foram reconstruídas e por consequência, aprimoradas.

Ao abordar a temática com o auxílio do aplicativo foi possível confirmar na prática as informações de Benini (2013) e Ribeiro (2017) de que o uso de tecnologias favorece o estudo nas aulas de Biologia do Ensino Médio. Neste ponto, é necessário fazer a ressalva de que se houvesse uma maior quantidade de computadores disponíveis para a turma haveria um maior aproveitamento da atividade, tanto pontualmente quanto e para assuntos e temas futuros. 


\section{Referências}

Benini, A. (2013). O uso de vídeos como ferramenta para auxiliar a compreensão em Anatomia e Fisiologia Humana na disciplina de Biologia. 2013. Disponível em: $<$ https://acervodigital.ufpr.br/handle/1884/51201 >. Acesso: 08-06-2020.

Baldo, A. P. V. (2017). "Uso de tecnologias digitais: relato de experiência do uso de aplicativo móvel como auxílio no processo ensino e aprendizagem de anatomia humana". 2017. Artigo (Especialização) - Curso de Docência na Educação Profissional, Universidade do Vale do Taquari - Univates, Lajeado. Disponível em: $<$ http://hdl.handle.net/10737/2029>. Acesso em 05-06-2020.

Brasil (2017). Base Nacional Comum Curricular (BNCC). Ministério da Educação, 2017. $572 \mathrm{p}$.

Carneiro, J. F. (2019) Levantamento e análise de aplicativos para dispositivos móveis, que possam ser utilizados no ensino de biologia, nos conteúdos anatomia e fisiologia humana. Universidade Tecnológica Federal do Paraná. Coordenação de Tecnologia na Educação. Especialização em Inovação e Tecnologias na Educação. 25p.

Correo Costa, L., Pansera-de- Araújo, M. C., \& Bianchi, V. (2017). Sistemas digestório, respiratório e circulatório Humanos em livros didáticos de Biologia de Ensino Médio. Bio-grafía, 10(18),P.19-27.

Human Anatomy Atlas 2018: Complete 3D Human Body. Version 2018.3.02. Argosy Publishing, Inc., 2018. Disponível em: $<$ https://www.microsoft.com/pt-br/p/humananatomy-atlas-2018-complete-3d-human >. Acesso: 27-11-2019.

National Geographic. (2010). A Incrível Máquina Humana. Disponível em: < https://www.youtube.com/watch?v=sJ67HAYiiUw>. Duração: 48min. Acesso: 0511-2019.

Oliveira, C., Moura, S.P. Sousa, E. (2015). TIC's na Educação: a utilização das tecnologias da informação e comunicação na aprendizagem do aluno. Pedagogia em Ação, ed.7, v.1 - Periódicos PUC - Minas.

Ribeiro, F. S. (2017). "Aprendendo Fisiologia”: Uma plataforma de ensino online como objeto de aprendizagem no ensino de Fisiologia Humana. Disponível em: < https://lume.ufrgs.br/handle/10183/169884 >. Acesso: 05-06-2020.

Rodrigues, D.; Wagner, C.; Luz da Costa, E. Uso dos celulares como recurso para aprendizagem de ciências: auxílio disponível para trabalhar fisiologia humana. Anais do salão internacional de ensino, pesquisa e extensão, v. 11, n. 1, 14 fev. 2020.

Silva, A. et al. (2017). Anatomia Digital: um Ambiente Virtual de Apoio ao processo Ensino-Aprendizagem. Disponível em: $\quad<$ http://www.brie.org/pub/index.php/sbie/article/view/7603 >. Acesso: 05-06-2020.

Wen, C. L. (2016). Homem Virtual (Ser Humano Virtual 3D): A Integração da Computação Gráfica, Impressão 3D e Realidade Virtual para Aprendizado de Anatomia, Fisiologia e Fisiopatologia. 2016. Disponível em: 
<http://gradmais.usp.br/wp-content/uploads/2016/07/01_Chao.pdf >. Acesso: 0106-2020.

\section{Agradecimentos}

A CAPES, pelo apoio à pesquisa dos mestrandos do ProfBio. 